\title{
NotAs SOBRE A SEMÂNTICA do SUFIXo '-VEL': A EXPRESSÃO DA MODALIDADE NO PB
}

\section{Some comments on the semantics of the sufix 'vel': expressing modality in Brazilian Portuguese}

\author{
Roberta Pires de Oliveira* \\ Francisco Muleka Ngoy**
}

Parte de um projeto maior de estudos sobre a modalidade no português brasileiro (PB), essa pesquisa se ancora num conceito não tradicional de modalidade, que é, por isso, discutido explicitamente na primeira seção. O objetivo deste artigo é analisar a semântica do sufixo 'vel' quando ele expressa possibilidade. Após definirmos modalidade, mostramos, na segunda seção, que esse sufixo é ambíguo, podendo expressar: uma propriedade inerente ao objeto, uma certa "obrigação" moral e possibilidade. A seção 3 apresenta uma descrição rudimentar desses usos, com o intuito de isolar apenas a expressão da possibilidade. A próxima seção introduz o modelo de Kratzer $(1981 ; 1991)$ para a modalidade nas línguas naturais. Em seguida, na seção 5 , aplicamos essa proposta para o sufixo '-vel'. Mostramos que esse sufixo expressa possibilidade quando combinado com verbos transitivos (ou transitivizados), que ele se combina apenas com base circunstancial e que admite apenas duas fontes de ordenação: normalidade e deôntica. Esses resultados, comparados com o que ocorre nos modais plenos, mostram que o sufixo de possibilidade é menos dependente do contexto.

*Professora Doutora na graduação em Letras e na pós-graduação em linguística da Universidade Federal de Santa Catarina, Pesquisadora do CNPq

**Graduando do curso de Letras na Universidade Federal de Santa Catarina 


\section{A Modalidade em Sentido Estrito.}

Como dissemos, é necessário iniciar com uma breve excursão pelo conceito de modalidade porque neste artigo entendemos modalidade de uma maneira mais restrita do que se encontra normalmente na literatura, em especial nas análises funcionalistas ou de cunho descritivo. Nessa tradição, além de modalidade recobrir uma área muito mais ampla do que pretendemos abarcar com a nossa pesquisa, o modo como o fenômeno é compreendido gera, como mostraremos adiante, resultados inadequados porque não condizem com os dados. Para exposição breve da vertente funcionalista nos ancoramos na proposta teórica de Palmer (2001). ${ }^{1}$

$\mathrm{O}$ autor define a modalidade como a expressão da subjetividade ou da opinião do falante. Essa definição é ampla demais para os nossos objetivos, porque ela coloca na mesma "caixinha" fenômenos muito diferentes. Afinal, nessa perspectiva, as sentenças abaixo são modais.

(1) Lamento a morte do leiteiro.

(2) Infelizmente, o leiteiro morreu.

(3) O leiteiro pode ter morrido.

É de se notar, em primeiro lugar, que se pode, com muito mais facilidade, afirmar que as sentenças em (1) e (2) expressam a opinião do falante do que a sentença em (3). De fato, a sentença em (3) pode não exprimir literalmente a opinião ou subjetividade do falante, mas uma constatação, uma inferência que expressa uma possibilidade resultante de uma avaliação "objetiva", por assim dizer; isto é, tendo em vista o que se sabe sobre os fatos do mundo, é possível concluir que o leiteiro morreu. ${ }^{2}$ Veja que esse é certamente o caso da sentença em (4):

\section{(4) Necessariamente os corpos caem.}

Desse ponto de vista, a definição dada por Palmer não permite captar o fenômeno que nos interessa descrever e que aparece em (3) e (4), a não ser que torçamos a definição de modalidade dada acima de forma que ela capte também os julgamentos da física que, neste caso, passam a ser "subjetivos". Kratzer (1981) dependa desse conceito que é definido em Kratzer (2002) 
Além disso, há diferenças estruturais acentuadas entre (1) e (2), de um lado, e (3) e (4), de outro. Em primeiro lugar, em (1), o sujeito do verbo 'lamentar' é 'eu' que se refere ao falante; mas em (3), 'o leiteiro', embora seja o sujeito gramatical da sentença, não é argumento de 'poder', como veremos com mais detalhes na terceira seção; que este é o caso pode ser constatado pelo fato de que essa sentença pode ser parafraseada por:

(5) Pode ser que o leiteiro morreu.

'Lamentar' é um predicado que pede um argumento externo, enquanto 'poder' é um "inacusativo" que pede uma proposição como complemento. Sua estrutura é, então, a de um operador proposicional: Pode (proposição). ${ }^{3}$

Se, agora, comparamos (2) e (4), veremos que o advérbio em (2) de fato se refere à avaliação do falante com relação à afirmação sobre a morte do leiteiro; enquanto que em (4) uma descrição semelhante é inadequada, porque o que parece ocorrer neste caso é que o advérbio modaliza a proposição, afirmando que ela é uma necessidade. Em outros termos, em (2) o advérbio efetivamente não faz parte do conteúdo proposicional expresso; enquanto que em (4) o advérbio é parte do conteúdo. Reside aí uma diferença importante: na visão funcionalista, a modalidade não afeta o conteúdo proposicional que está sendo expresso ${ }^{4}$; enquanto que na proposta que estaremos desenvolvendo, a modalidade afeta o conteúdo proposicional.

Assim, em (4) temos uma proposição complexa, isto é, formada por uma outra proposição; em outros termos, o advérbio atua sobre o conteúdo proposicional gerando uma nova proposição. A mesma diferença se aplica às sentenças (1) e (3): em (1) o falante coloca sua opinião sobre a proposição que expressa a morte do leiteiro, sem alterá-la; já em (3), o que há é uma proposição em que a proposição que expressa a morte do leiteiro é alocada no espaço da possibilidade, isto é, afirma-se a proposição complexa de que há uma possibilidade do leiteiro ter morrido.

Embora não seja nossa intenção mostrar que efetivamente sentenças como (3) e (4) expressam proposições complexas, um argumento que se pode oferecer a favor dessa descrição é o fato de que é possível haver iteração de modais, como exemplificado em $(6)^{5}$ :

\footnotetext{
Ver, por exemplo, Mioto et al. (2006) e Stowell (2004).

Segundo von Fintel (2006), essa concepção pode ser traçada até Kant em sua Crítica da Razão Pura, e aparece explicitada também em Frege. Para tanto ver von Fintel (2006).
} 
OLIVEIRA, R. P. de.; NGOY, F. M. NOTAS SOBRE A SEMÂNTICA DO SUFIXO ‘-VEL'...

(6) É possível que os visitantes tenham que sair às 5.

Se a modalidade não interfere na proposição, não há como explicar que pode haver modalidade de modalidade. Mas é isso precisamente o que ocorre em (6).

Neste artigo estamos interessados em sentenças como (3) e (4), que são exemplos de sentenças modais, na acepção explicitada por von Fintel (2006): "a modalidade é entendida como uma predicação de segunda ordem, que pode expressar tanto necessidade quanto possibilidade." ${ }^{6} \mathrm{Ou}$ seja, temos modalidade sempre que for possível detectar um operador de possibilidade ou de necessidade. Veja que nas sentenças em (1) e (2) não há nem um nem o outro. Nesta perspectiva, uma sentença modalizada constitui uma proposição complexa ("uma predicação de segunda ordem") em que um operador de necessidade ou de possibilidade atua sobre a proposição gerando uma nova proposição.

Há vários modos de expressar modalidade nas línguas naturais. Em (7), o morfema '-vel' indica possibilidade; a sentença em (8) exemplifica um uso de um modal pleno 'pode'; enquanto que em (9) temos uma perífrase modal 'dá pra/de V'; e, em (10), temos um advérbio 'possivelmente':

(7) Essa ilha é visível (daqui da janela).

(8) Essa ilha pode ser vista (daqui da janela).

(9) Dá pra/de ver essa ilha (daqui da janela).

(10) Possivelmente vemos essa ilha (daqui da janela).

Cada uma dessas formas de expressar a modalidade demanda uma análise pormenorizada, além de uma discussão sobre se elas são ou não sinônimas. Aparentemente não são; com (7) afirma-se a possibilidade física de se ver a ilha, enquanto que em (8) veicula-se não apenas a possibilidade física da ilha ser vista, mas ela pode também indicar permissão. Note que em (10) indaga-se sobre a possibilidade de se ver a ilha; não há certeza de que seja possível vê-la.

As sentenças acima não esgotam o inventário de estruturas modais no PB. A modalidade pode ser disparada sem nenhuma marca linguística visível. Por exemplo, a sentença em (11) abaixo é ambígua: ou afirma que se pode andar até no máximo $60 \mathrm{~km} / \mathrm{h}$ ou que essa é a velocidade mínima; em outros termos que se pode andar até $60 \mathrm{~km} / \mathrm{h}$ ou que se deve andar a no mínimo $60 \mathrm{~km} / \mathrm{h}$ :

6
either necessity or possibility." 
OLIVEIRA, R. P. de.; NGOY, F. M. NOTAS SOBRE A SEMÂNTICA DO SUFIXO ‘-VEL'..

(11) O limite de velocidade é de $60 \mathrm{~km} / \mathrm{h}$.

Já em (12), afirma-se que João pode (tem a capacidade de) falar inglês.

(12) O João fala inglês.

Não é possível dar conta de todos esses casos num único artigo. É por essa razão que este artigo se concentra num único problema, deixando os demais para pesquisas futuras: atenta-se para a expressão da possibilidade através do sufixo '-vel', sem, no entanto, ter qualquer pretensão de uma análise morfologia mais rigorosa. Nosso interesse é estritamente semântico, embora nossa esperança seja que a análise semântica possa servir de suporte a outras.

\section{Uma Primeira Olhada Para o Sufixo '-Vel’}

Encontramos em Celso Cunha (1976, p. 72), por exemplo, a seguinte descrição do sufixo '-vel':

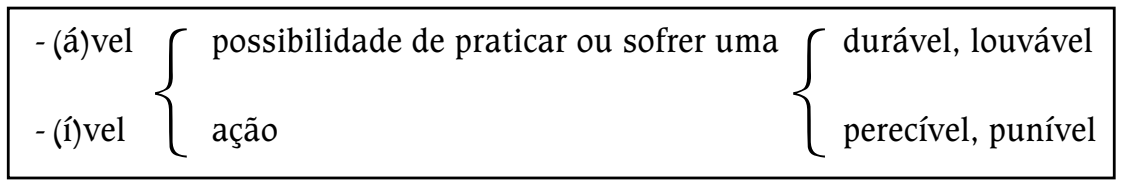

Há vários pontos a serem considerados a partir dessa citação. 0 primeiro é que ela é prototípica, no sentido de que o mesmo conteúdo se encontra em outras gramáticas. Assim, parece ser consenso que esse sufixo indica possibilidade. A literatura em linguística também afirma o mesmo, como pode ser atestado na citação a seguir: "Uma forma como -vel, por exemplo, presente em palavras como dobrável, reversível, não existe independentemente de uma Regra de Formação de Palavras que forma adjetivos a partir de verbos em português com o significado "que pode ser X-do' (onde X representa o verbo derivante)...” (ROSA, 2000, p. 69).

Então, aparentemente não há nada de novo em considerar '-vel' um morfema que indica possibilidade. Mas o fato é que essas análises não fazem juz à semântica desse sufixo, quer porque desconsideram o fato de que pode haver mais de um morfema '-vel', quer porque afirmar que ele indica possibilidade é pouco para entendermos a sua semântica.

Se atentarmos para os exemplos de Cunha, vemos que não é sempre possível parafrasear o adjetivo acompanhado pelo sufixo por uma sentença 
modal expressando possibilidade, nem pela paráfrase sugerida por Rosa: 'que pode ser X-do'. Considere 'durável' na sentença abaixo (ou em qualquer outra, na verdade):

(13) Essa pilha é durável.

Em (13) não se está afirmando da pilha que ela pode durar -veja que a paráfrase proposta por Rosa não se aplica-, mas que ela efetivamente dura, ou seja, que ela tem a propriedade de durar. Trata-se, aparentemente, de um tipo de sentença genérica. Genéricos podem ser interpretados como modais $^{7}$ que expressam "necessidade" fraca. Esse parece ser mesmo o caso porque é possível parafrasear (13) por: em geral essa pilha dura ${ }^{8}$.

Já 'louvável' veicula um outro significado que para poder ser parafraseado como possibilidade deve receber uma interpretação de "obrigação":

(14) A atitude de João é louvável.

Como podemos perceber, em (14) não se afirma que é possível louvar a atitude do João, mas que a atitude dele é digna de ser louvada. Trata-se da expressão de um tipo de obrigação. Nesse caso, a paráfrase proposta por Rosa se aplica: A atitude de João que pode ser louvada..., embora seu resultado não seja de todo satisfatório porque, intuitivamente, a sentença não veicula a possibilidade de se louvar a atitude de João, mas algo como: deve-se louvar a atitude de João. Ela expressa uma obrigação moral, muito mais do que uma possibilidade.

Talvez 'perecível' seja um caso de expressão de possibilidade, se estivermos certos de que ele expressa a possibilidade de perecer, mas pode ser o caso que ele expresse uma propriedade que certos objetos têm e neste caso, ele estaria mais próximo do exemplo em (13). Apenas 'punível' é um exemplo claro de expressão de possibilidade, no sentido de ser passível de punição:

(15) Sua atitude é punível.

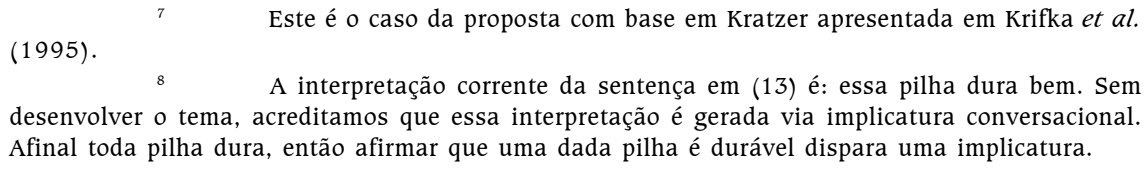


Mais uma vez, a paráfrase de Rosa se aplica: Sua atitude que pode ser punida... A conclusão é que o sufixo parece exprimir mais do que simples possibilidade.

No Dicionário Houaiss da Língua Portuguesa (2004), aprendemos que '-vel' vem do latim e indica "ser passível de ou ser agente de". No entanto, se observarmos os exemplos, verificamos, mais uma vez, que é possível distinguir classes de significado: a expressão de uma possibilidade; de uma obrigação moral e, finalmente, há o caso, não descrito explicitamente pelo dicionário, em que se expressa uma propriedade do objeto; esses são os exemplos em (16):

(16) formidável (que é admirável), favorável (que favorece), razoável (que tem plausibilidade / que tem razão de ser), imprestável (que não presta), sensível (que sente)...

Neste último caso, entram os exemplos que Rosa considera como sendo já lexicalizados, porque não mais produtivos, como: 'amável' (que é gentil) e 'considerável' (que é grande, como em: a literatura sobre o assunto é considerável).

Utilizando o corpus do Projeto NURC, rastreamos os usos de 'vel'. Encontramos 235 exemplos de palavras com este morfema. Destes, retiramos os exemplos de 'possível' (e derivados, 'impossível'). Separamos os exemplos em três classes de significado, levando em conta o contexto em que os adjetivos apareciam: expressão de propriedade, expressão de obrigação moral e expressão de possibilidade.

Na próxima seção, apresentamos uma descrição pouco detalhada dessas classes já que a nossa intenção é apenas delimitar a classe da possibilidade. Um problema que não iremos discutir diz respeito a definirmos se no caso desse sufixo estamos diante de ambiguidade ou se é possível agruparmos todos ou alguns desses significados numa mesma entrada lexical. Vamos, por questão de comodidade, entender que se trata de ambiguidade e nos concentrar na expressão da possibilidade. Quando isso ocorre? Qual é a estrutura semântica nesse caso? Como é que o falante sabe que ele tem que acionar o operador de possibilidade? São algumas das perguntas que tentaremos responder nas próximas seções.

\section{Delimitando o ‘-Vel’ de Possibilidade}

O primeiro uso que gostaríamos de isolar é aquele em que o sufixo expressa uma propriedade, como exemplificado em (13): 'durável', que dura; 
'amigável', que é amigo; 'considerável', que deve ser considerado. Como dissemos, talvez seja possível considerar esse uso como um caso de genérico, um tipo de modalidade, mas não iremos desenvolver esse tópico. ${ }^{9}$

Os deverbais são, com certeza, modais, porque ou expressam um certo tipo de obrigação moral ou possibilidade. A determinação de um ou de outro está vinculada ao tipo semântico do verbo do qual o adjetivo se deriva. Considere o caso de 'lamentável' exemplificado na sentença abaixo:

(17) Esse ato é lamentável.

O verbo subjacente é 'lamentar', 'esse ato' é o argumento interno e $o$ argumento externo parece ser indeterminado, o que se verifica pela presença de um tipo de passiva, clara na paráfrase a seguir: Esse ato deve ser lamentado. Veja, mais uma vez, que não se veicula a possibilidade de se lamentar, mas que houve um fato que deve ser lamentado. Essa interpretação só ocorre quando o verbo do qual se deriva o adjetivo é um factivo e expressa a atitude do falante frente ao evento descrito pela proposição. Os exemplos são: 'lamentar', 'louvar', 'rir'.

Considere, agora, a sentença abaixo:

(18) Esse livro é publicável.

Um primeiro aspecto a ser notado é que esse tipo de construção só é possível quando o verbo de base é transitivo ou passível de uma interpretação transitiva. Intransitivos e inacusativos resistem à combinação com este sufixo:

(19) * a. Esse número é telefonável.

* b. João é saível.

* c. A carta é chegável .

(19b) é aceitável se entendermos 'sair' como um verbo biargumental, sinônimo de 'sair com'. Nesse caso, ele foi transitivizado. Não fomos capazes de levantar um exemplo de verbo mono-argumental que funcionasse com o sufixo. Mas nem todos os verbos bivalentes podem se combinar com ele, as sentenças abaixo parecem estranhas:

(20) a. * Esse livro é escrevível.

b. * Essa casa é construível.

esse uso não é derivado de um nome. 
Talvez uma investigação sobre a acionalidade (os exemplos em (20) são accomplishments) desses verbos pudesse nos dar alguma luz. Não fizemos essa investigação, porque estamos interessados em entender como a modalidade é expressa nas línguas naturais. Basta, por enquanto, notar que há restrições de combinação: o verbo de base precisa ser bi-argumental (embora essa condição não seja suficiente).

Em termos de estrutura, 'esse livro' em (18) não é argumento externo de 'publicar', mas seu argumento interno. Mais uma vez, o argumento externo está indeterminado, em um tipo de passiva: Esse livro pode ser publicado. A diferença com relação à sentença em (17) é a presença implícita da possibilidade.

Esta seção delimitou, minimamente, o conjunto de exemplos com '-vel' que expressam possibilidade, afastando os outros casos, porque esse é o nosso objeto de estudos.

\section{A Análise da Modalidade em KRATZER}

O famoso artigo de Kratzer (1981) é considerado o fundador do quadro teórico atual na linguística de cunho formal. ${ }^{10} \mathrm{~A}$ autora mostra que há de fato diferentes modos de modalidade, como já mencionamos acima, inclusive o sufixo '-able' em inglês, mas sua análise se detém nos chamados verbos modais plenos, mais particularmente nos modais em alemão ('müssen', por exemplo), mas é evidente que ela pretende ser não apenas trans-linguística, mas cobrir todos os vários modos de exprimir a modalidade.

Sua proposta parte da seguinte constatação: uma sentença modal, como em (21) abaixo, é altamente indeterminada, no sentido de que ela pode receber diferentes leituras a depender do contexto em que ela ocorre:

(21) João pode se casar.

Note como a interpretação dessa sentença se altera conforme alteramos o fundo conversacional em que ela é proferida:

Situação A: João acabou de fazer 21 anos e a lei vigente em seu país diz que só é possível casar (sem autorização dos responsáveis) quando se tem mais de 21 anos de idade.

\footnotetext{
Para uma apresentação detalhada e formal do modelo de Kratzer, que está fortemente ancorado em Lewis, ver Pires de Oliveira e Mortári (2007)
} 
OLIVEIRA, R. P. de.; NGOY, F. M. NOTAS SOBRE A SEMÂNTICA DO SUFIXO '-VEL'...

Situação B: O falante não tem certeza de que João vai mesmo se casar, mas por todos os indícios que ele tem (por exemplo, ele sabe que João foi fazer o cursinho de noivos), ele conclui que João pode se casar.

Situação C: O João é um solteirão e já está com seus 50 anos. Não há nenhuma evidência de que ele esteja planejando o casamento; o falante quer, no entanto, indicar que há possibilidade de ele se casar.

Embora seja possível imaginar essa sentença proferida em outras situações, essas já são suficientes para entendermos o problema da indeterminação ${ }^{11}$. Na situação em A, trata-se de uma permissão de acordo com as leis vigentes. É, pois, uma interpretação deôntica, a lei permite o casamento. Já em B, não se trata de uma permissão, mas de uma conclusão a partir de evidências do mundo. Podemos, grosseiramente, dizer que estamos diante de uma leitura circunstancial, porque estamos lidando com evidências circunstancialmente relevantes. Já em C, trata-se simplesmente da expressão de uma probabilidade. Em todos esses casos se expressa uma possibilidade, diferentemente do que ocorre em (22):

\section{(22) João tem que casar.}

A sentença em (22) expressa necessidade. Essa sentença também é passível de receber diferentes leituras: deôntica (a lei exige que ele case, porque, por exemplo, ele deu sua palavra); circunstancial (por tudo o que o falante sabe, ele conclui que necessariamente é o caso do João casar); de desejo (o falante expressa seu desejo de que João se case)...

A solução proposta por Kratzer entende, seguindo o que já se sabia na semântica de mundos possíveis, que um modal pode expressar possibilidade ou necessidade. Esta é a sua Força Modal. 'Poder' expressa possibilidade (grosseiramente traduzida por: em pelo menos um mundo é o caso que a); enquanto 'tem que' expressa necessidade (também rudimentarmente traduzida por: em todos os mundos é o caso que a). Evidentemente, essa não pode ser toda a estória sobre os modais, em particular porque ela não é suficiente para apreendermos a indeterminação que descrevemos acima.

Mas também porque se nos contentarmos com essa descrição seremos obrigados a dizer que a sentença em (21) é trivialmente verdadeira, porque, sem nenhum tipo de restrição, o domínio do operador é o universo de discurso, isto é, todos os mundos e, é claro, nessa quantidade enorme de mundo é certo que haverá pelo menos um em que João casa. Sem a restrição

\footnotetext{
(2006).

Sobre a indeterminação ver Pires de Oliveira, Basso;e Mendes de Souza 
de acessibilidade de mundos, a sentença em (22) é necessariamente falsa, porque, mais uma vez, teremos que considerar que o domínio do operador é o universo de discurso e é certo que não é o caso que em todos os mundos o João é casado. Afinal ele ser casado não é uma verdade lógica. Precisamos, portanto, de um mecanismo para restringir o domínio do operador modal. Essa restrição explica, em parte, as diversas interpretações suscitadas pela sentença e na semântica de mundos possíveis é representada pela relação de acessibilidade.

Quando proferimos uma sentença como 'Todo mundo traz cerveja', restringimos o domínio de atuação do quantificador 'todo', que não age sobre o universo de discurso, mas é restrito a um grupo contextualmente saliente; por exemplo, aqueles que vão à festa. O mesmo ocorre com os modais. Kratzer entende que modais são quantificadores de mundos possíveis, cujo domínio de atuação é determinado pelo contexto. Assim, modais não são simplesmente operadores que tomam como argumento uma proposição - isto é, eles não têm uma estrutura como Pode $p$, como sugerimos anteriormente-, mas são predicados de dois lugares, que estabelecem uma relação entre um fundo conversacional (ou Base Modal), o domínio do operador, e a proposição. Em outros termos, modais são relações entre conjuntos de mundos e uma proposição. o primeiro argumento, que indica o conjunto de mundos relevantes, é, na maioria das vezes, preenchido contextualmente, mas ele pode aparecer explicitado, como ocorre na sentença em (23):

(23) Tendo em vista às leis que regem essa sociedade, João pode casar.

Essa sentença apresenta explicitamente a base modal, dada implicitamente na situação A: o operador de possibilidade atua apenas sobre os mundos cujas leis são como as dadas pela sociedade em questão. Com isso restringem-se os mundos sob os quais o quantificador irá atuar. Essa sentença é verdadeira, se, em pelo menos um desses mundos da base modal, João casa. Em outros termos, se em pelo menos um dos mundos cujas leis se conformam às leis da sociedade em questão, João casa. A diversidade de interpretações de sentenças modais se explica pelo fato de que a restrição do quantificador pode não aparecer explicitamente; nesse caso, a variável que indica os mundos a serem considerados (os mundos acessíveis) será, como ocorre com os pronomes, preenchida contextualmente.

Os mundos que constituem a base modal na situação B são outros. Por exemplo, neles a idade de João não é um fator determinante. Nessa situação, contam os mundos que condizem com os fatos que são do 
conhecimento do falante e que são relevantes; por exemplo, o fato de que João está fazendo o cursinho de noivos. Na base modal, agora, estão apenas os mundos em que este fato é verdadeiro. Portanto, o anteparo para interpretar (21) mudou e essa mudança explica porque a sua interpretação se alterou. O mesmo raciocínio vale para a situação em $\mathrm{C}$.

Há ainda um terceiro fator que determina a interpretação de sentenças modais. Trata-se do que Kratzer denominou Fonte de Ordenação. A fonte de ordenação também pode ser dada contextualmente. Grosseiramente ela organiza os mundos da base modal com relação a um mundo tomado como ideal. ${ }^{12}$ Os mundos da base modal estão mais próximos ou mais afastados do mundo tomado como padrão. Há assim uma ordenação entre os mundos que constituem a base. É essa ordenação que explica a diferença entre (21) e (24):

(24) É bem possível que João se case.

Sem entrar em grandes detalhes, veja que a possibilidade de João se casar é maior em (24) do que em (21), em especial se considerarmos seu proferimento na situação B. Suponha que o mundo ideal é o mundo em que João se casa. Considere, agora, (21), (24) e (25):

(25) É muito pouco possível que João se case.

A ideia básica é que a diferença entre essas sentenças, supondo que a base modal se mantenha constante, é que estamos ora mais próximos do mundo ideal, exemplo em (24), ora mais afastados, (25), ora expressando apenas a possibilidade, exemplo em (21).

A autora propõe que há apenas duas bases modais: a epistêmica, que diz respeito ao conhecimento, e a circunstancial, que indica os fatos relevantes numa dada situação. Essas bases são ordenadas diferentemente: tendo em vista as leis (deôntica), tendo em vista os objetivos do falante (teleológica), tendo em vista os desejos do falante, tendo em vista os fatos normais,... Assim, a base modal da sentença em (21) na situação A é circunstancial é sua fonte de ordenação é deôntica; na situação $B$, a base modal é circunstancial e a fonte de ordenação são os fatos tomados no seu curso normal (normalmente se faz cursinhos de noivos apenas se se pretende casar)...

12 Essa ideia é muito próxima da hipótese das esferas levantada por Lewis para dar conta das sentenças contrafactuais e mais particularmente para explicar certos encadeamentos nas sentenças contrafactuais. 
Essa é uma apresentação muito superficial da teoria de modalidade proposta por Kratzer, mas ela já é suficiente para colocarmos a questão que nos interessa e que, do que sabemos, não foi desenvolvida ainda em nenhuma análise: como é a modalidade expressa pelo sufixo '-vel'?

\section{A ModAlidADE DE '-VEL'}

Até este ponto fizemos uma apresentação que serve como fundo para colocar a questão sobre a qual gostaríamos de refletir: será que a modalidade é expressa da mesma maneira em todos os seus modos de manifestação? Em particular, será que quando temos o sufixo '-vel', na sua interpretação de possibilidade, temos as três instâncias que aparecem na análise dos modais: a força modal, a base modal e a fonte de ordenação? Será que o sufixo é mais ou menos dependente de informações contextuais?

Intuitivamente, uma sentença como (26) indica que é possível calcular a área em questão.

(26) Essa área é calculável.

Nesse caso, a força modal é possibilidade, isto é, existe pelo menos um mundo pertencente à base modal em que há um resultado para o cálculo da área.

Vale a pena aqui fazer uma pequena digressão antes de enfrentarmos nosso ponto central, porque ela diz respeito a um tipo de exemplo que encontramos com bastante frequência no corpus analisado e que merece um dedo de reflexão:

(27) Essa música é escutável.

O problema é que sem maiores informações contextuais (27) veicula que a música em questão não é lá grande coisa, "dá pra escutar essa música, mas...". Não vamos desenvolver esse ponto, mas não é difícil ver uma solução para este problema em termos de implicatura: por que é que um falante diria de uma música que ela é possível de ser escutada, isto é, que há pelo menos um mundo na base modal em que ela é escutada, se é óbvio que músicas são escutáveis? Afinal, ser passível de ser escutada parece ser parte da definição mesma de música (ao menos numa situação de normalidade). Se o falante diz o óbvio é porque ele quer dizer que esse é o máximo de informação que ele pode dar sobre a música; o que dispara imediatamente uma implicatura. 
OLIVEIRA, R. P. de.; NGOY, F. M. NOTAS SOBRE A SEMÂNTICA DO SUFIXO ‘-VEL'...

Mas voltemos ao exemplo em (26). Podemos, então afirmar, com uma certa tranquilidade, que há um operador modal de possibilidade. 0 problema é de onde vem esse operador? Se supomos que ele é fornecido pelo sufixo, temos um problema, porque há casos como (17), 'Este ato é lamentável', em que se expressa um dever: esse ato deve ser lamentado; e casos como 'amigável', que podemos descrever como contendo um operador genérico. Logo, a informação sobre a força modal não pode ser dada no léxico, como ocorre com os modais plenos (como 'poder'). No caso dos deverbais, a força modal parece estar dada pela combinação do sufixo com o verbo: verbos de atitude proposicional (como 'lamentar') disparam interpretação de dever, de obrigação; já verbos transitivos indicam possibilidade.

Além dessa diferença, o sufixo parece não permitir uma diversidade de leituras como aquela apresentada pelos modais plenos e exemplificada acima no exemplo em (21). Do que pudemos analisar a partir dos dados do NURC, o sufixo pode receber apenas dois tipos de interpretação e a base modal é sempre circunstancial, isto é, os mundos acessíveis são aqueles compatíveis com os fatos relevantes no mundo de avaliação. Não encontramos nenhuma ocorrência com base modal epistêmica. Talvez essa restrição explique o estranhamento de uma sentença como (28) abaixo:

(28) Os objetos são atraíveis pela Terra.

Note que 'atrair' é um verbo transitivo. Por que, então, a sentença em (28) é estranha? Porque a base modal é epistêmica, já que diz respeito ao nosso conhecimento sobre o mundo. Se for isso, estamos diante de uma restrição semântica: o sufixo expressa possibilidade apenas com base modal circunstancial.

Considere, agora, o exemplo:

(29) Este projeto é viável.

"Out-of-the-blue" só sabemos que há pelo menos um mundo em que o projeto se concretiza (o sufixo se combina com um verbo transitivo e indica, portanto, possibilidade), mas veja como a interpretação se altera nos seguintes contextos:

Situação A: trata-se de um projeto de iniciação científica e se está avaliando a possibilidade de ele ser levado a cabo. Neste caso, por tudo o que o falante sabe sobre o projeto em questão, sobre o que é um projeto de IC, sobre o tempo de duração... ele avalia que o projeto pode ser executado. Temos, então, uma base circunstancial: dados os fatos relevantes, é possível 
concluir que o projeto pode ser executado a contento.

Situação B: trata-se de um projeto de edificação de um prédio e está sendo avaliada a possibilidade de construção tendo em vista o projeto diretor da cidade, as leis de construção da cidade. Neste caso estamos diante de uma base deôntica: tendo em vista o que a lei determinada, esse edifício pode ser construído.

No corpus avaliado só encontramos casos como o descrito pela situação A: casos em que a base modal é circunstancial e os mundos são organizados segundo um padrão de normalidade. Exemplos como o da situação B, em que a base modal circunstancial é ordenada segundo as leis, são, no entanto, possíveis. Mas esses são os dois únicos casos de fonte de interpretação.

A sentença em (26) só pode receber a interpretação com fonte de ordenação de normalidade; enquanto que para a sentença em (25) é possível, além da interpretação de normalidade, uma fonte de ordenação deôntica: segundo as leis vigentes, essa música pode ser escutada. Imaginemos uma situação em que se está vivendo um regime ditatorial e que há uma censura sobre o que se pode e o que não se pode ouvir. Neste caso, há uma interpretação deôntica para a sentença. A hipótese que estamos lançando é que a possibilidade expressa através do sufixo '-vel' é menos indeterminada, isto é, menos dependente do contexto, porque ela só se ampara em uma base modal, a circunstancial, e se combina apenas com duas fontes de ordenação: a que indica normalidade (a maior parte dos exemplos) e a deôntica. A conclusão é que com a sufixação a dependência contextual é menor, embora a sua força seja dada não pelo sufixo, mas pelo tipo semântico do verbo.

\section{ESPECULANDO}

A análise da semântica do sufixo '-vel' mostrou que ele é ambíguo: ele expressa uma propriedade inerente ao objeto, uma obrigação moral ou uma possibilidade. Embora não tenhamos desenvolvido o tema, apontamos que esses diferentes usos se unem por expressarem modalidade. Nosso trabalho se concentrou na expressão da possibilidade e na aplicação do modelo de Kratzer $(1981 ; 1991)$. Mostramos que a força modal não está lexicalmente codificada, mas depende da combinação do sufixo com o tipo semântico do verbo do qual o adjetivo se deriva: verbos de atitude proposicional geram interpretação de dever, enquanto que verbos transitivos engendram possibilidade. Atentando para esse último caso, vimos que ele se combina apenas com base circunstancial - estamos, então, diante de 
uma restrição semântica -, que seleciona os mundos que são compatíveis com os fatos relevantes no mundo de avaliação. Esses mundos são ordenados segundo duas fontes: a de normalidade e a deôntica.

Se compararmos o sufixo com os modais plenos, notamos algumas diferenças: nos modais plenos a força modal é codificada lexicalmente ('pode' só pode expressar possibilidade), enquanto que a força modal do sufixo depende do tipo de verbo do qual o adjetivo deriva; sentenças com modais plenos são mais indeterminadas do que aquelas com adjetivos formados pelo sufixo. Esses só requerem uma base modal circunstancial e a fonte de ordenação é, na grande maioria, a da normalidade, embora possamos criar exemplos de fonte de ordenação deôntica. Esses são indícios de que a modalidade no sufixo é menos dependente do contexto.

\section{RESUMO}

Este artigo investiga a semântica do sufixo '-vel' no português brasileiro. Mostramos que esse sufixo é ambíguo, podendo expressar: uma propriedade inerente ao objeto, uma obrigação ou uma possibilidade. Uma descrição dessas classes serve de amparo para uma análise pormenorizada da expressão da possibilidade, tendo em vista que o objetivo é entender a modalidade no PB. Adotando o modelo de Kratzer $(1981 ; 1991)$, apresentado no artigo, mostramos que o sufixo não tem uma força dada lexicalmente, mas ela é resultado da combinação com o tipo semântico do verbo: verbos de atitude proposicional geram interpretação de dever, enquanto que verbos transitivos geram possibilidade. Analisando esse último caso, verificamos que ele se combina apenas com base modal circunstancial, e a fonte de ordenação é ou de normalidade (todos os casos encontrados no corpus do NURC) ou deôntica. Esses resultados indicam que a interpretação do sufixo é menos dependente do contexto do que a dos modais plenos.

Palavras-chave: Semântica; Modais; Possibilidade; Sufixo.

\section{ABSTRACT}

The paper investigates the semantics of the suffix '-vel' in Brazilian Portuguese. The suffix is ambiguous. It may express the inherent property of an object, a moral obligation, or a possibility. The description of these three classes backgrounds a detailed analysis of the expression of possibility. Kratzer's proposal $(1981,1991)$, presented in section 4 , is applied to the expression of possibility. It shows that the suffix does not have 
its modal force lexically encoded, but that it is derived from its combination with the verb semantic type: verbs of propositional attitude engenders a "must" reading, whereas its combination with transitive verbs conveys possibility. The analysis of possibility shows that the suffix only combines with a circumstantial modal basis, and the ordering source is either normality or deontic. Thus, it is less dependent on context than plain modal verbs.

Keywords: Semantics; Modal; Possibility; Sufix.

\section{REFERÊNCIAS}

CASTILHO Ataliba T.; CASTILHO, Célia Maria M. de. Advérbios Modalizadores. In: ILARI, Rodolfo (Org.). Gramática do Português Falado. v. II.. Campinas: Editora da Unicamp, p. 213-260, 1992.

CUNHA, Celso. Gramática do Português Contemporâneo. 6 ed. Belo Horizonte: Bernardo Álvares S.A., 1976.

HOUAISS, A.; VILLAR, M. de S. Dicionário Haouaiss da Língua Portuguesa. Rio de Janeiro: Objetiva. 2004.

FINTEL, Kai von. Modality and Language. Disponível em: <http://mit.edu/fintel/www/ modality.pdf>. 2006.

KRATZER, Angelika. The Notional Category of Modality. In: EIKMEYER, H-J; RIESER, H. (Eds.). Words, worlds, and contexts: new approaches to word semantics. Berlin: de Gruyter, 1981. p. 38-74.

. Modality. In: STECHOW, A. V.; WUNDERLICH, D. (Ed). An International Handboook of Contemporary Research. Berlin: De Gruyter. 1991. p. 639-650.

Facts, particulars or units of information? Semantik Archives, 2002.

KRIFKA, M. et al. Genericity: an introduction. In: CARLSON, G; PELLETIER, F.J. (Ed.). The Generic Book. Chicago: The University of Chicago Press. 1995. p. 1-124.

MIOTO, Carlos; SILVA, Maria Cristina Figueiredo; LOPES, Ruth Vasconcelos. Manual de Sintaxe. Florianópolis: Insular. 2006.

PALMER, Robert. Mood and Modality. Cambridge: Cambridge University Press, 2. ed. 2001.

OLIVEIRA, Roberta Pires de; BASSO, Renato M.; SOUZA, Luisandro M. de. o que há nas sentenças comparativas? Um exercício de análise. 2006. Enviado para publicação.

OLIVEIRA, Roberta Pires de; MORTÁRI, César. Uma Introdução à Semântica de Mundos Possiveis para as Línguas Naturais. 2007.Em preparação.

ROSA, Maria Carlota. Introdução à Morfologia. São Paulo: Contexto. 2000.

STOWELL, Tim. Tense and Modals. In: GUÉRON, J.; LECARME, J. (Ed.). The Syntax of Time. MIT Press, 2004. p. 621-636.

Submetido em: 17/03/2007.

Aceito em: 08/11/2007. 